\title{
FROM ARCHIVE DOCUMENTATION TO ONLINE 3D MODEL VISUALIZATION OF NO LONGER EXISTING STRUCTURES: THE TURIN 1911 PROJECT
}

\author{
D. Einaudi ${ }^{1}$, A. Spreafico ${ }^{1, *}$, F. Chiabrando ${ }^{1}$, C. Della Coletta ${ }^{2}$ \\ 1 DAD, Department of Architecture and Design, Politecnico di Torino, Viale Mattioli 39, 10125 Torino \\ (davide.einaudi,alessandra.spreafico,filiberto.chiabrando@polito.it) \\ 2 DAH, Division of Arts and Humanities, University of California San Diego, USA (cdellacoletta@ucsd.edu)
}

Commission II, WG II/8

KEY WORDS: 3D modelling, 3D reconstruction, archive data digitization, photogrammetry, cultural heritage

\begin{abstract}
:
Rebuilding the past of cultural heritage through digitization, archiving and visualization by means of digital technology is becoming an emerging issue to ensure the transmission of physical and digital documentation to future generations as evidence of culture, but also to enable present generation to enlarge, facilitate and cross relate data and information in new ways. In this global effort, the digital 3D documentation of no longer existing cultural heritage can be essential for the understanding of past events and nowadays, various digital techniques and tools are developing for multiple purposes.

In the present research the entire workflow, starting from archive documentation collection and digitization to the 3D models metrically controlled creation and online sharing, is considered. The technical issues to obtain a detail 3D model are examined stressing limits and potentiality of $3 \mathrm{D}$ reconstruction of disappeared heritage and its visualization exploiting three complexes belonging to 1911 Turin World's Fair.
\end{abstract}

\section{INTRODUCTION}

Nowadays, digital tools allow the reconstruction of no longer visible cultural heritage based on different sources, testing various processes for manifold purposes. The choice of which digital techniques and strategies are the best to be applied for the virtual reconstruction is determined by the available sources and by the final level of detail that need to be achieved. Last but not least, diverse objectives influence the results, but the use of $3 \mathrm{D}$ digital reconstruction is reported in different disciplines to support various analysis and consideration: hypothetical reconstruction giving life to never realized projects from original drawings (Apollonio et al., 2017), mean to support restoration in case of destruction (Bitelli et al., 2017), diachronic visualization of lost constructive phases of urban heritage and repositories of historical photos of architectures connected to a 4D web viewer (Münster et al., 2020, RodriguezGonzálvez et al., 2019).

As regards the possible approaches, reconstruction based on old images or frames extracted from ancient videos constitute one possible method to extract the shape of the object; nonetheless more than one image or more frames captured with different point of view are necessary. Despite low resolution and lack of camera parameters/information, images not captured with photogrammetric requirements have been proved to be an interesting source of information exploiting photogrammetric data processing, especially SfM algorithms (Beltrami et al., 2019, Maiwald et al., 2017). Despite this kind of images lacks of metric information and the integration with measurements is necessary, different researches combined dimensions contained in original drawings (Condorelli, Rinaudo, 2018), coordinates obtained with current Terrestrial Laser Scanning (TLS) or topographic data of the same object or of the unchanged context (Beltrami et al., 2019, Maiwald et al., 2017, Bitelli et al., 2017) allowing to use them for extracting metric information for digital reconstruction.

Nonetheless, these approaches are supported by a collection of historical photos or by the integration with the survey of the unchanged context to recreate the old state of the considered element.

What can be done if both the architecture and its surroundings are not the same as the past and only a few old data can document the old version? This is the case of the 'Turin 1911' project, here considered to explore integration between a considerable amount of drawings and few images as a basis to digitally reconstruct the $3 \mathrm{D}$ models of three case studies. The aim is not limited to the 3D visualization, but some potentiality of the obtained 3D models constitute the first step to assist interdisciplinary research.

\section{TURIN 1911 PROJECT}

\subsection{The 1911 World's Fair in Turin}

'Turin 1911' is a joint project between Politecnico di Torino and University of California San Diego (UCSD), involving a multidisciplinary team it aims to digitally recreate the Turin 1911 World's Fair, testing how traditional research and digital technologies can mutually assist the study of a lost universe, the exposition is considered as phenomenon expression of $\mathrm{XX}$ century ideology and place of modernity and progress (http://www.italyworldsfairs.org/). Celebrating the 50th anniversary of national unity, the 1911 International Exposition of Industry and Labour (Della Coletta, 2006, Bassignana, 2001,

\footnotetext{
* Corresponding author
} 
Moriondo, 1981, La guida, 1911) took place in Turin, first capital of the Italian Reign, cradle of Risorgimento and industrial Italian capital at that time. Considering this background, the event was the occasion to reinforce the role of Turin in national and international context, raising popular consensus and showing the economic, political and social power through a presentation of astonishing architectures enriched with masterpieces of visual arts - and exposing each kind of human mind elements as expression of the culture and national identity. The Valentino Park, historical site of the expositions, was chosen for its natural magnificence, but required to be expanded covering more than one million of meters squares, hosting twenty nations and reaching more than seven million of visitors. All the structures, excluding sporadic exceptions, were conceived ad hoc for the event as ephemeral buildings, they were built with wood structure covered with plaster and have been demolished or abandoned after the exposition closure. Only a few historical monumental architectures, already existing before the 1911 Fair, are today still standing. 3D modelling of two surviving complexes Valentino Castle and Medieval Hamlet - have been analysed based on a multi-scale, multi-sensor and hybrid approach as the first challenge of the project (Chiabrando et al, 2019). The second step was focused on the survey and modelling of the entire park. This objective was achieved thanks to an high resolution aerial photogrammetric acquisition carried out in 2018. The flights, carried out by the AVT-Airborne Sensing/Terra Messflug for the municipality of Torino, were achieved using the UltraCam Eagle Mark 2 acquiring only the nadir view. The images - acquired at $1470 \mathrm{~m}$ height - have a Ground Sample Distance (GSD) of $7 \mathrm{~cm}$ and have been processed in Agisoft Metashape using as internal (camera calibration) and external (position and attitude of the different images) orientation parameters the ones provided by the company using some Check Points topographically measured on the field. Digital products - point cloud, 3D Mesh and orthophoto - have been generated reporting the current state of the public space (Figure 1). The third phase addresses the 3D modelling of those ephemeral architectures no longer existing through a digital reconstruction based on available documentation, a theme that is developed in the present research.

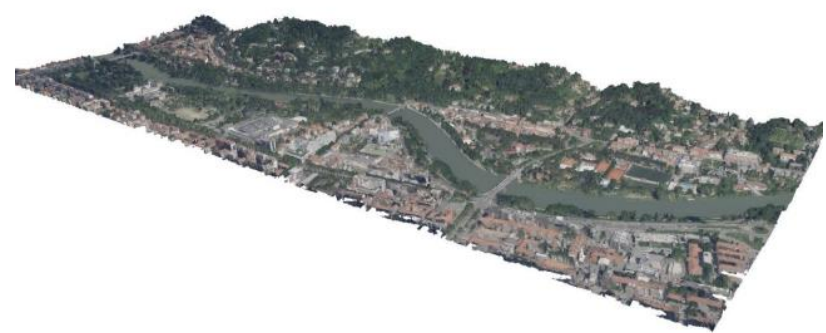

Figure 1. A view of the textured mesh of current state of the Valentino Park and its surroundings obtained with the aerial photogrammetric acquisition

\subsection{Three case studies}

More than one hundred structures (national, region, province, city and colonial pavilions, services buildings, bridges, manufacturing pavilions) were widespread in the event area. Between them, three different structures have been chosen as emblematic case studies for their differences in dimension, style and geometrical complexity. The analysed building are: the Pavilion of the City of Turin, the Pavilion of Hungary and the spectacular complex involving the Monumental Bridge, the Monumental Waterfall and the Courtyard of Honour (Figure 2).

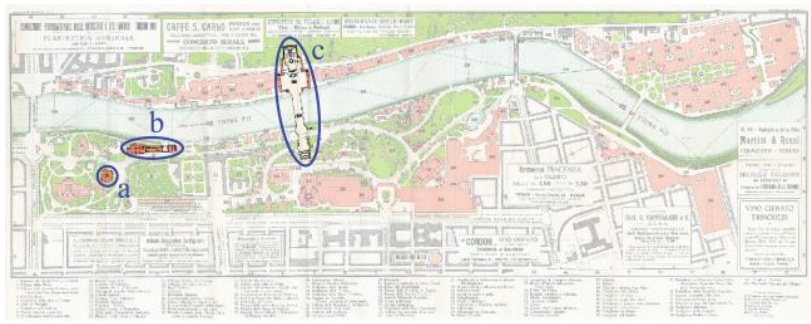

Figure 2. The three case studies in the general plan of the entire 1911 World's Fair (CDC private collection): (a) the Pavilion of the City of Turin, (b) the Pavilion of Hungary, (c) the

Monumental Bridge, the Monumental Waterfall and the Courtyard of Honour

The City of Turin and the Monumental complex are both expression of the revival style of Neo-Baroque turning to Filippo Juvarra and are characterized by white surfaces that gave the title 'white city' to the entire exposition. This architectural style has been designed by the Italian trio of engineers Pietro Fenoglio, Giacomo Salvadori di Wiesenhof and Stefano Molli and proposed as model to identify the united Italy (Della Coletta, 2006).

The Pavilion of the City of Turin (Figure 3), designed as a central-plan palace surmounted by a dome, occupied a covered area of $1400 \mathrm{~m}^{2}$ (La guida, 1911). The Monumental Bridge, the Monumental Waterfall and the Courtyard of Honour (Figure 4) were visually a unique complex representing a fabulous scenario. The five bridge arches were enriched with columns supporting Winged Victories; the external structure hid a triple tunnel in the lower level equipped with a tapis roulant to connected the two sides of the River Po in a $107 \mathrm{~m}$ path. The bridge was associated with the spectacular Monumental Waterfall laid on the hill through the courtyard of Honour, an articulated space surrounded by two arcaded wings and a system of terraces and stairs. Two towers, $80 \mathrm{~m}$ high, framed the Waterfall introducing the ascent to the top of the theatrical scene (La guida, 1911). The Pavilion of Hungary (Figure 5), covering $6000 \mathrm{~m}^{2}$ near the river Po, was an unusual building composed by flanked blocks with pyramidal towers representing the 'Attila's tend' and constituted a landmark in the exposition; designed by the Hungarian Emily Töry, Maurice Pogány and Dénes Györgyi with vivid colours, the Pavilion was in contrast to the 'white city', but it was the last example of a Hungarian national style (Cornaglia, 2001).

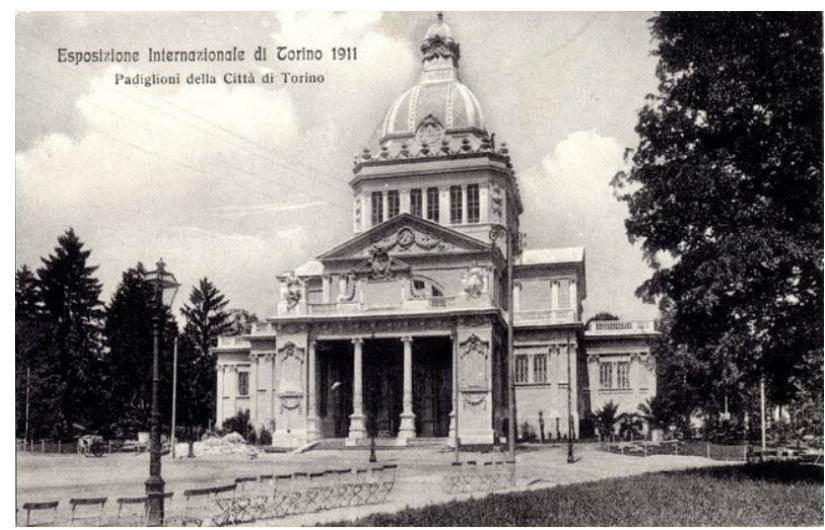

Figure 3. 1911 Postcard of the Pavilion of the City of Turin (CDC private collection) 


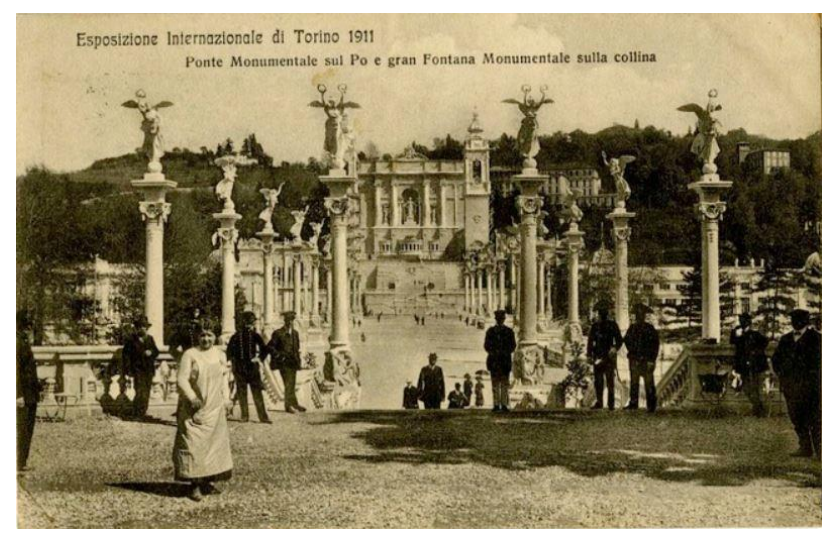

Figure 4. 1911 Postcard of the Monumental Bridge with the Courtyard of Honour and the Monumental Waterfall in the background (CDC private collection)

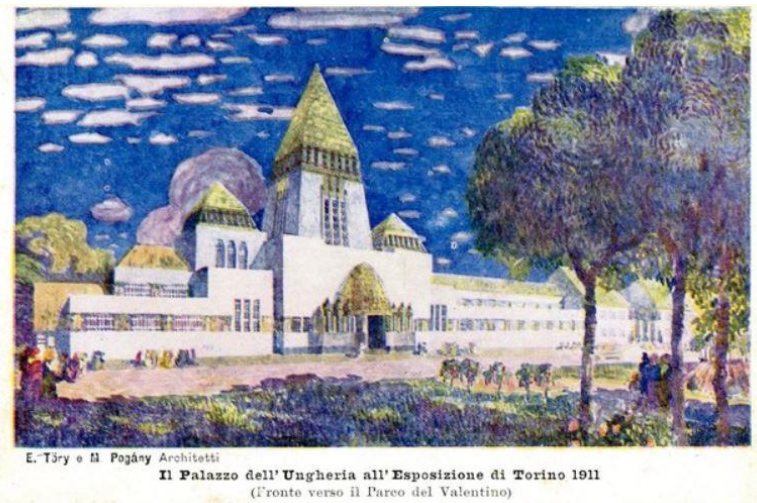

Figure 5. 1911 colour postcard of the Pavilion of Hungary (CDC private collection)

Fragmented and unclassified data about Turin 1911 Exhibition are today available in different archives, books and newspapers spread all over the world, but also online.

\section{THE PROCESS OF DIGITAL RECONSTRUCTION}

As regards the collection of visual material, only a few images postcards and pictures are available. Most of them are postcards and sketches and cannot be useful for photogrammetric process, while the few photos - dated back to the 1910's - are taken from the same point of view for the City of Turin. The Hungary Pavilion is captured when the building was still under construction or the photo are foreshortened view; in the case of the Monumental complex the photos are taken far away, so the quality is too low (Figure 4) to extract information about the shape. Due to these limits of historical images, the process of digital reconstruction based only on them is not suitable. The archival research has reported the discovery of the Stefano Molli archive, containing a collection of 588 sheets dedicated to the 1911 Exposition and preserved by Fondazione Marazza of Borgomanero (NO). The Pavilion of the City of Turin and the Monumental complex are conceived and planned by Stefano Molli, as its numerous and detailed technical drawings can prove. In fact, 85 sheets define the complexity of bridge, courtyard and waterfall (Figure 6), while 30 represents the City of Turin. The archive material comprises only technical drawings, varying from a scale of $1: 2000$ up to $1: 10$ for decorations, but with few annotations relating one drawing to another and distinguishing between old and new proposals. While for the Pavilion of Hungary only 6 drawings have been found.
The discover of huge number of technical drawings, their metric content and high level of detail suggest to perform a 3D modelling using as starting point the original drawings. Nonetheless, some discrepancies between data appear, in fact this technical documentation represents the project phase, so differences between the designed structure and the real built one - detectable by historical images - can occur.

The results obtained by the research of historical data have influenced the entire process; therefore a combined workflow exploiting technical drawings - that provide dimensional support - and images - to verify the effective shape - is proposed:

1. Data collection and analysis

2. Digitization process of drawings

3. 2D digital redrawing and correspondence verification of technical drawings

4. Understanding the compositive schema and identification of repetitive elements

5. 3D modelling and correction of the model according to the images

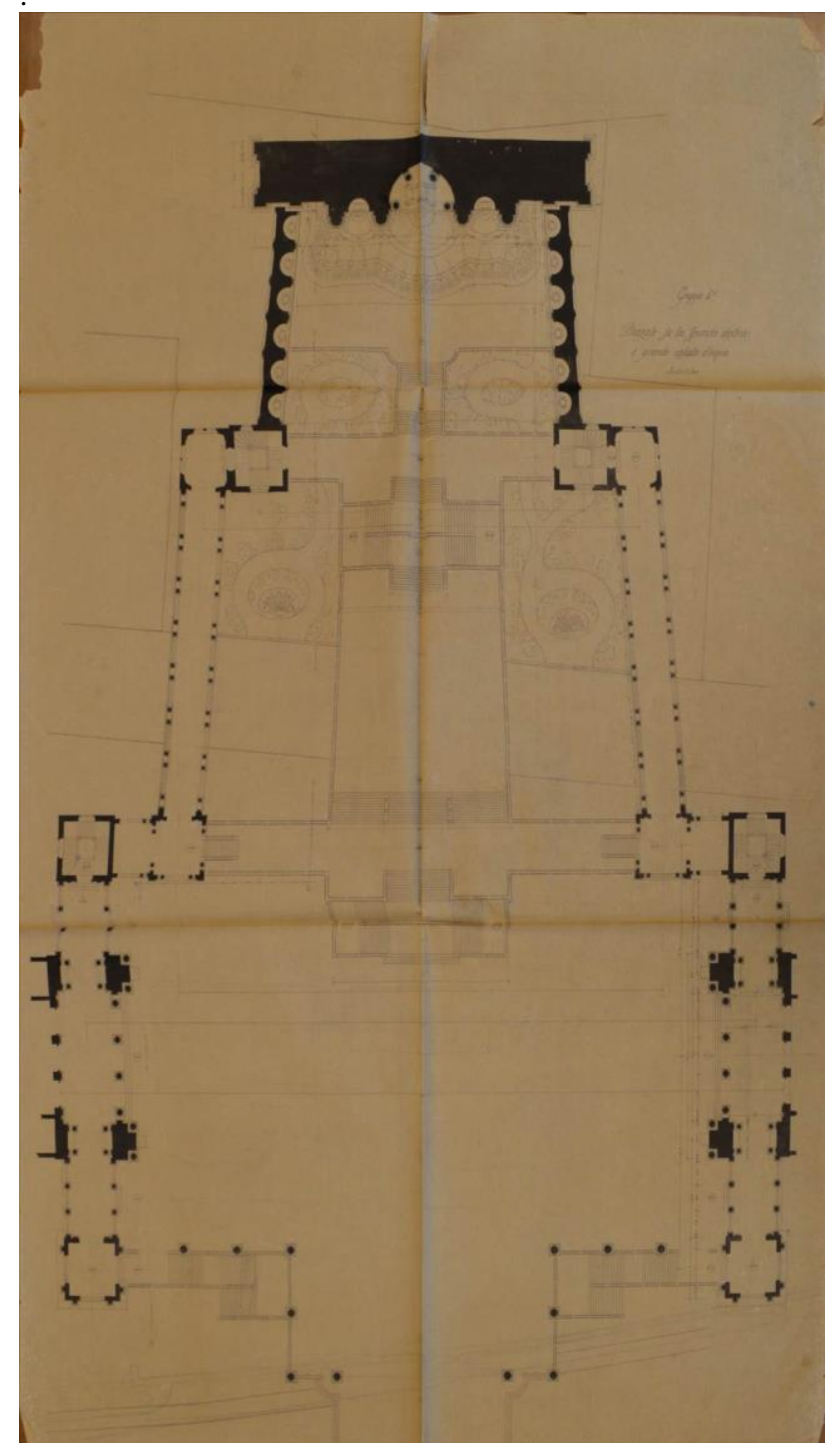

Figure 6. Plan of the Monumental Waterfall and Courtyard of Honour, original scale 1:100 (Fondazione Marazza, Archivio Stefano Molli) 

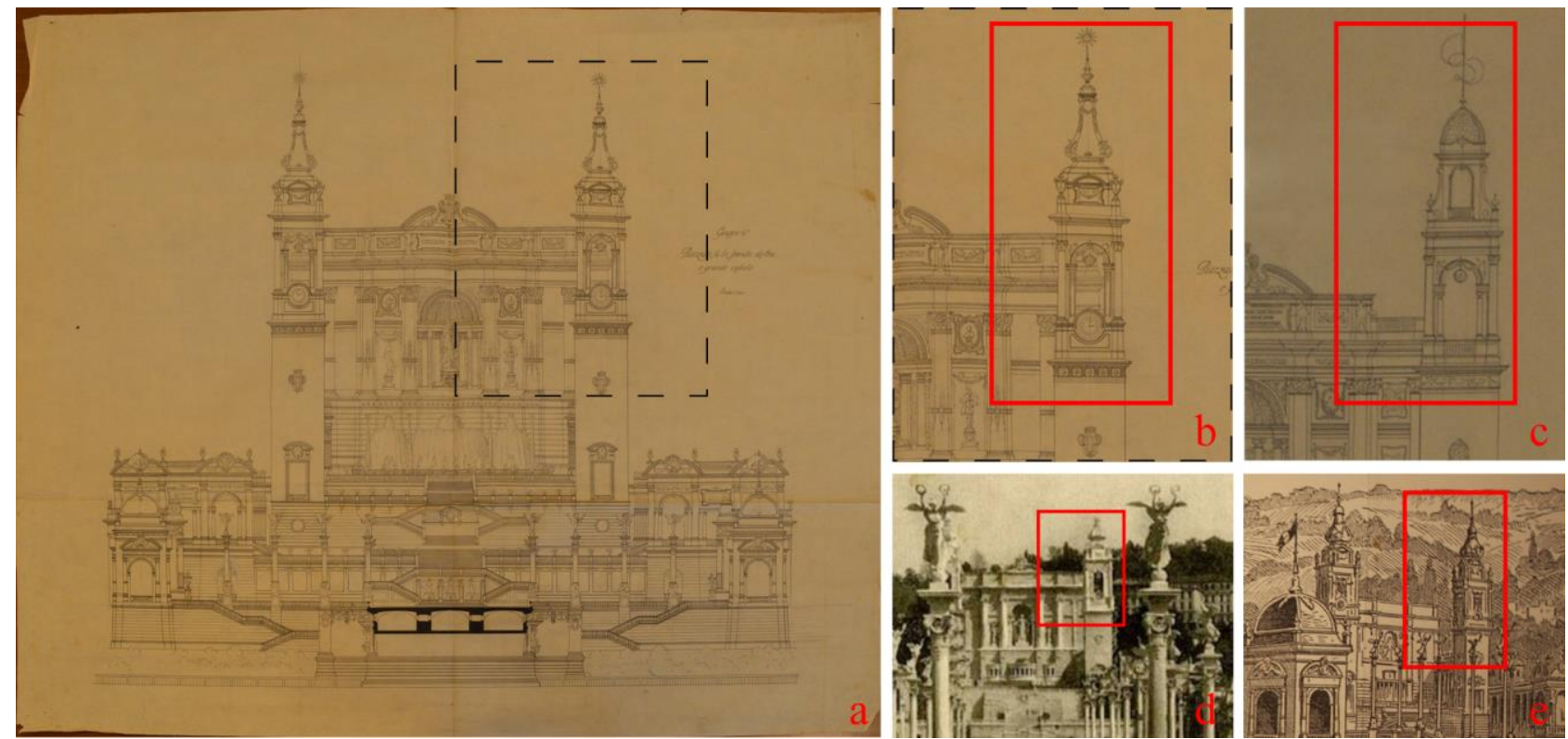

Figure 7. Comparison of different sources: (a) Elevation of the Monumental complex, original scale 1:100 (Fondazione Marazza, Archivio Stefano Molli), (b) zoom on the tower top and ledge, (c) same elevation in another drawing at original scale of 1:200

(Fondazione Marazza, Archivio Stefano Molli, (d) photo excerpt (CDC private collection), sketch excerpt (Exposition, 1911)

After data collection, both images and drawings require to be compared because they lack descriptions, such as annotation reporting data, project or survey drawing, which building or portion is represented. Therefore joining different visual documentation is necessary to understand the content and to verify the as built composition of the architecture, as in the case of the Monumental complex where a change of the tower and ledge design is visible in two different drawings at different scales, the image confirms the configuration of the 1:100 scale drawing, status also depicted in a meticulous and reliable sketch (Figure 7). This accurate observation enables the operator to select the most reliable drawings to be considered.

Subsequently the data analysis, the digitization of fragile $\mathrm{XX}$ century drawings is one key factor influencing the final metric quality of the $3 \mathrm{D}$ models. This procedure is quite challenge because of the dimensions of the drawings (also more than $3 \mathrm{~m}$ length), the presence of creases and the unavailability of a proper scanner. Therefore, as first attempt the drawings have been digitized employing a Digital Single Lens Reflex (DSLR) camera - Nikon D3200 with $18 \mathrm{~mm}$ lens - and testing image orthorectification and photogrammetric approach, in particular $\mathrm{SfM}$ solution. For small drawings a single shot was enough for the orthorectification using scale bars. While for large format drawings more images have been acquired with a photogrammetric approach, then they have been processed with SfM software (Agisoft Metashape) in order to align the photos, correct the lens distortions, scale the model (in this case some scale bars were employed) and finally to obtain a rectified image. Further tests will be considered to improve the digitization process of this challenging material. The so digitized drawings constitute the graphic reference for the following phase. After that the documents have been redrawing in 2D using a CAD environment (Autodesk Autocad). During the process the presence of quotations provides the mean to accurately dimension drawings with different scales in the same geometrical system, also enabling to correct errors contained in folded drawings (Figure 8). The geometrical relations between plans, sections and elevations is verified in CAD environment, providing the correct basis for the $3 \mathrm{D}$ modelling.

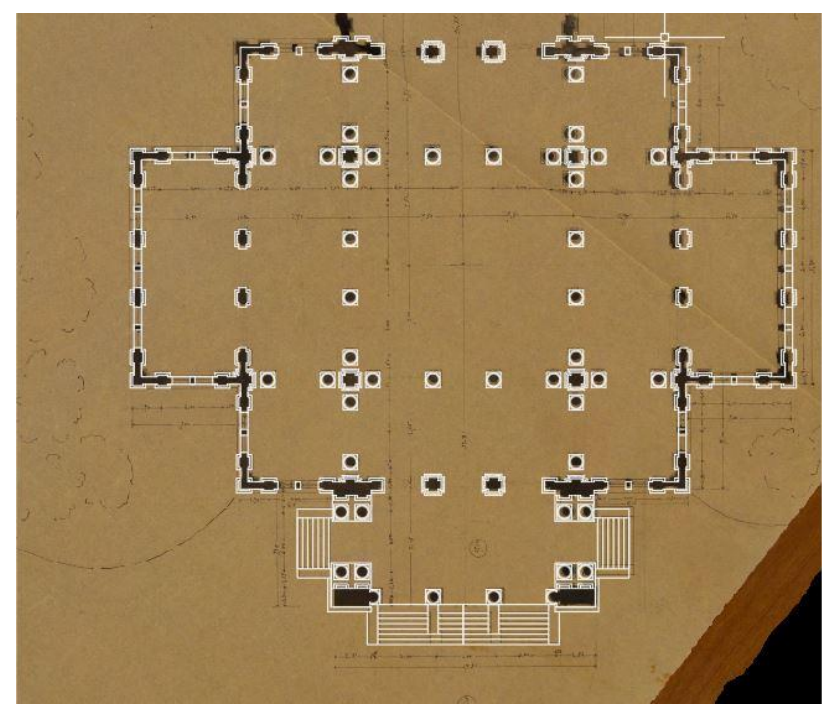

Figure 8. 2D redrawing on the digitized drawing of the plan of the City of Turin (Fondazione Marazza, Archivio Stefano

Molli), in the upper right part the shift between the re-drawings on the basis of the quotation and the digital drawing is evident.

The identification of compositive schemas, as symmetries and repetitive elements, enable to speed up both the re-drawing and the $3 \mathrm{D}$ modelling phases. Once the $2 \mathrm{D}$ digital drawings were manually created, they were imported in the 3D modelling software (SketchUp Pro). The choice of this kind of software is due to its flexibility and speediness during the modelling phase, assisted by the compatibility of CAD drawing that constitutes the basis for the 3D modelling. The dimension of the architectures and the complexity of most elements can be faced by this software also thanks to groups and components that ease the process and its organization. The use of $3 \mathrm{D}$ component is applied for repetitive elements (capitals, vases, statues, columns), this procedure boosts the modelling phase, enabling to modify the shape of all the same components operating only on one of them, but also reducing the file size of the model. 
Furthermore, some plugins allow to simplify and speed up the modelling phase. In particular, CleanUp automatically verify the boundaries of the geometries, erase overlapping faces and unify coplanar faces, reducing the number of elements and the file size. JHS powerbar contains a lot of commands that facilitate the modelling of complex components, in this case it is specially employed for the automatic recognition of faces in CAD drawings to ease the extrusion of elements. While Fredo6 Joint Push Pull allows extruding one or more faces at the same time along an axis chosen by the operator, also in case of curved surfaces, speeding up the creation of similar elements. $1001 \mathrm{Bit}$ Tool contains a series of command to assist the operator during the design of tailored elements, in the present cases especially in the modelling of doors and windows. During the modelling phase, the comparison between photos and the model based on drawing is extremely important to adjust the model to the real built structure (Figure 9). This process is possible thanks to the Match Photo tool, based on the reconstruction of the vanishing points of the perspective of the photo. Using this tool, starting from the model it is possible to orient the photo identifying corresponding vertical and horizontal axes between the model and the image; in the present works the use of this strategy allows to model new portions - not designed in the drawings but really built - according to the information reported in the oriented photo.

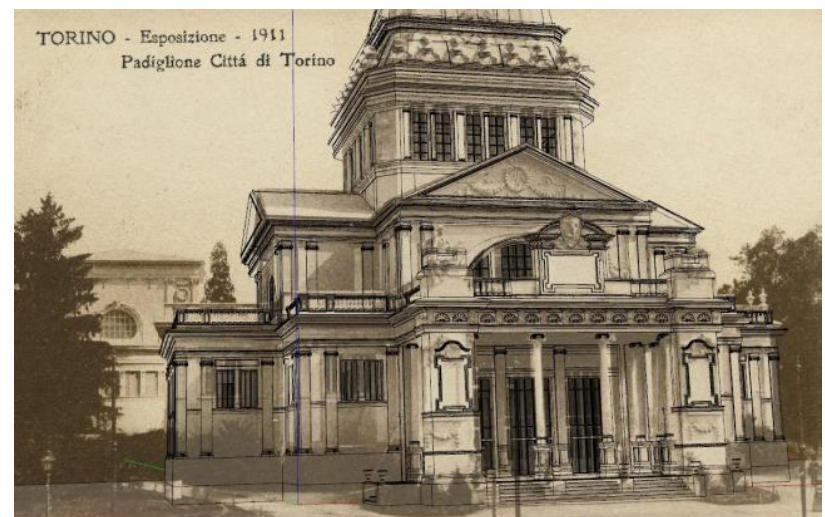

Figure 9. Image oriented with Match Photo tool to verify the model based on the original drawings

The available documentation has permitted only the exterior reconstruction of each pavilion, reaching a high level of detail (Figure 10, 11, 12); while the geometry is reconstructed, the application of correct materials requires further historical analysis.

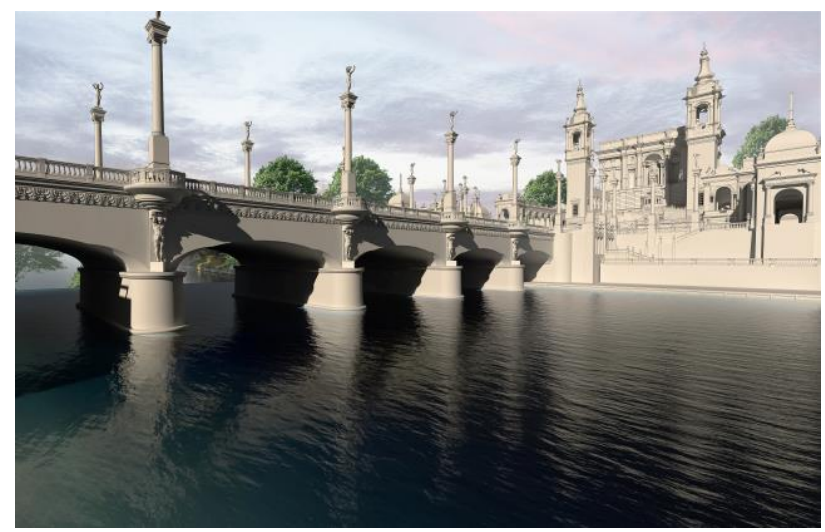

Figure 10. Final 3D model of the Monumental complex

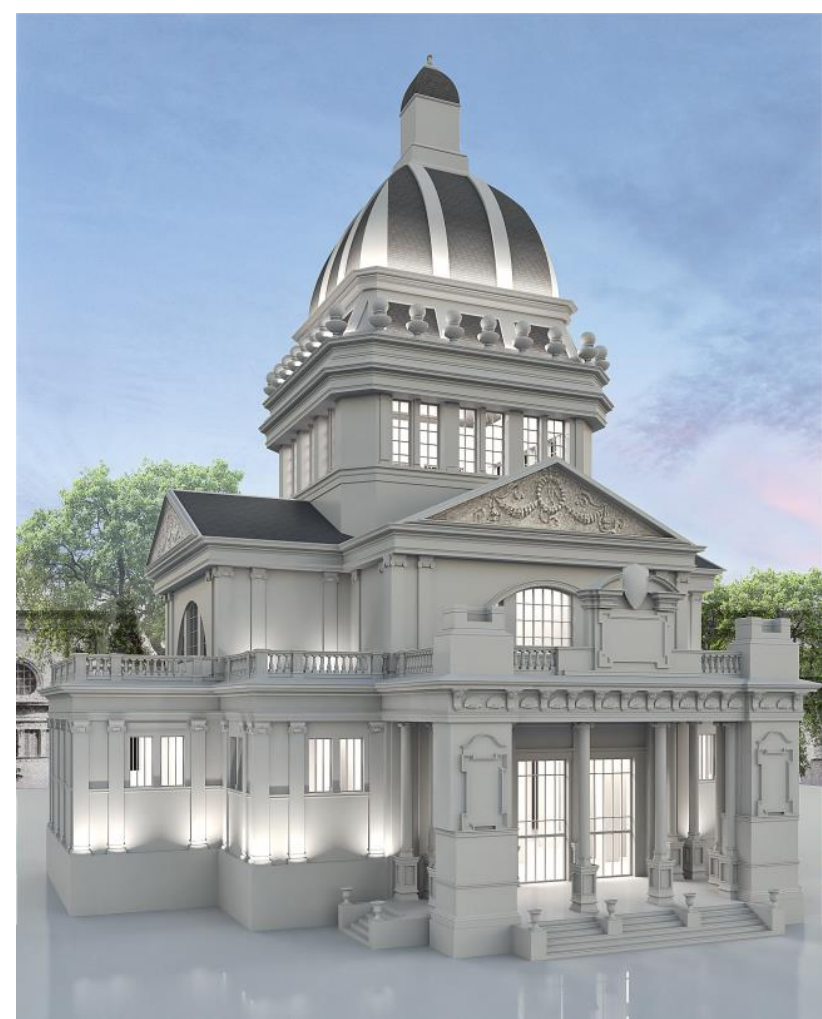

Figure 11. Final 3D model of the Pavilion of the City of Turin

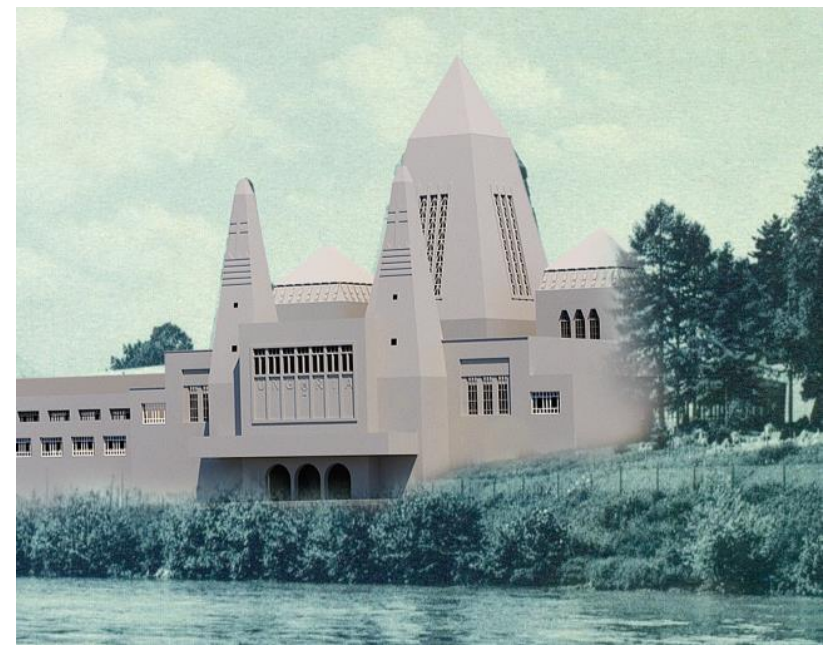

Figure 12. Final 3D model of the Pavilion of Hungary

The most relevant challenges faced during the modelling phase are common to the three structures: the management of different sources (drawings and images), their discrepancies and various level of scales have been solved by the operator using the same common reference system; the modelling of a lot of elements and of complex shapes has been facilitated thanks to plugins and tools available in a unique software, instead of using different software to perform different tasks and then combining the results. According to the dimension and presence of decoration, the characteristics of each model vary in a number of 3D components, file size and surfaces. In Table 1 the characteristics of each model are reported in skp and obj formats, as the former is the proprietary file while the latter is widely adopted as an interchangeable and open format. The larger file size of the Pavilion of the City of Turin than the Pavilion of Hungary is relevant, this is due not to the physical dimension of the Pavilion (in fact he Hungary is bigger than the 
City of Turin), but to the presence of a greater number of decorations and their shapes complexity that imply a higher number of faces; this is significant especially in obj format where some polygons are subdivided in triangles increasing the file size.

\begin{tabular}{|l|c|c|c|}
\hline Model & $\begin{array}{c}\text { Pavilion of } \\
\text { Hungary }\end{array}$ & $\begin{array}{c}\text { Pavilion of } \\
\text { City of Turin }\end{array}$ & $\begin{array}{c}\text { Monument } \\
\text { al complex }\end{array}$ \\
\hline 3D components & 835 & 664 & $358^{\circ} 798$ \\
Surfaces of skp & $327^{\circ} \cdot 950$ & $5^{*} 442 \cdot 846$ & $39^{\circ} 096 \cdot 764$ \\
File size skp (MB) & 21 & 41 & 353 \\
Surfaces of obj & $714^{\circ} 846$ & $6 \cdot 662 \cdot 139$ & $67 \cdot 422 \cdot 817$ \\
File size obj (MB) & 39 & 520 & $4 \cdot 460$ \\
Time (day) & 13 & 14 & 36 \\
\hline
\end{tabular}

Table 1. Characteristics of each model

\section{VISUALIZATION OF 3D MODELS}

3D models enable other experts, students and the general public to visualize and explore architectures no more surviving, but still existing in documentation not easily accessible and readable for everyone as technical drawing or texts. The online experience is particularly relevant to increase the dissemination of these results that are comfortably accessible at home through a device, like a laptop or a smartphone, especially useful in case of inaccessible archives and laboratories. In the present case, the obtained 3D models can be used in different ways: realistic views, desktop/online visualization of the single model and visualization in the actual context are here considered.

Realistic views, as in the case of the Courtyard of Honour (Figure 13), are obtained with rendering plugin (V-Ray) to provide the idea of the architecture in the natural environment.
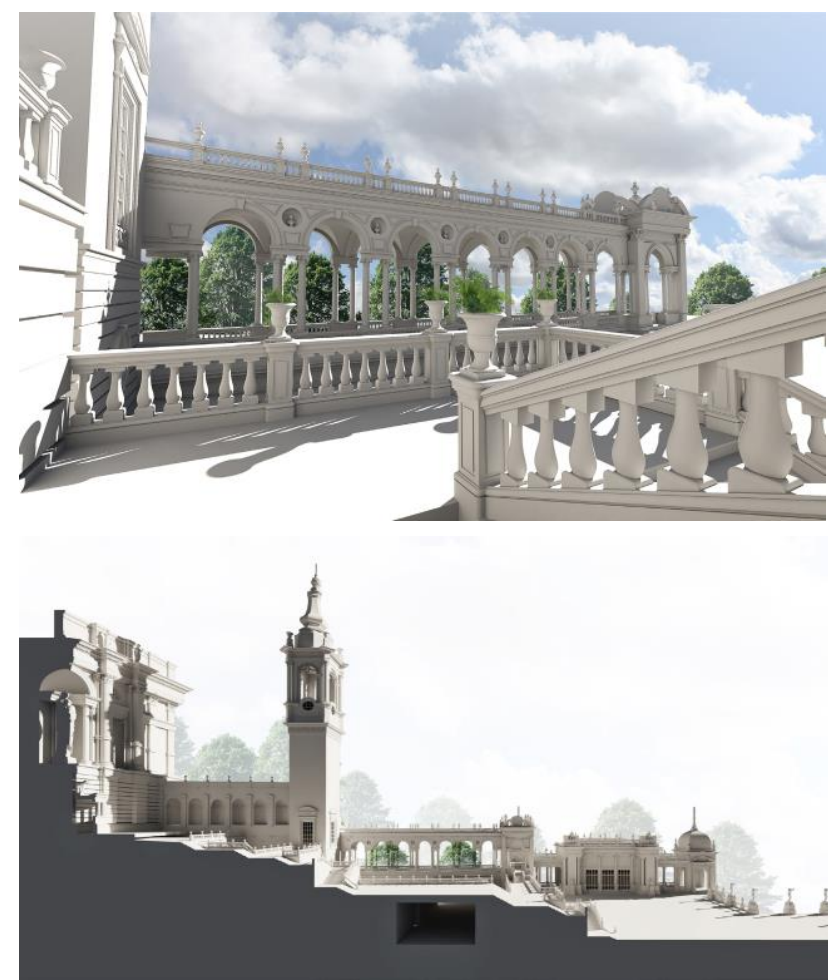

Figure 13. Realistic views of the of the Courtyard of Honour 3D model

Another possibility offered by a 3D model is its visualization in desktop or online applications (SketchUp Viewer). Desktop visualization (Figure 14) offers a variety of pre-set tools to navigate and modify the style of display. While the online viewing is available through a link permitting only the free navigation or selection of predefined views, but it works with different devices, pc, tablet or smartphone. The SketchUp Viewer app for mobile devices enables further tools to customize the styles of visualization and to take measures (Figure 15). At the same time, the Ar Modeling Viewing allows the Augmented Reality (AR) function. Both the opportunities constitute interesting means to assist no specialists in the navigation of the reconstructed architecture. Each model is available in the desktop visualization, while for the online one only the models of the Hungarian Pavilion and the City of Turin can be visualized until now.

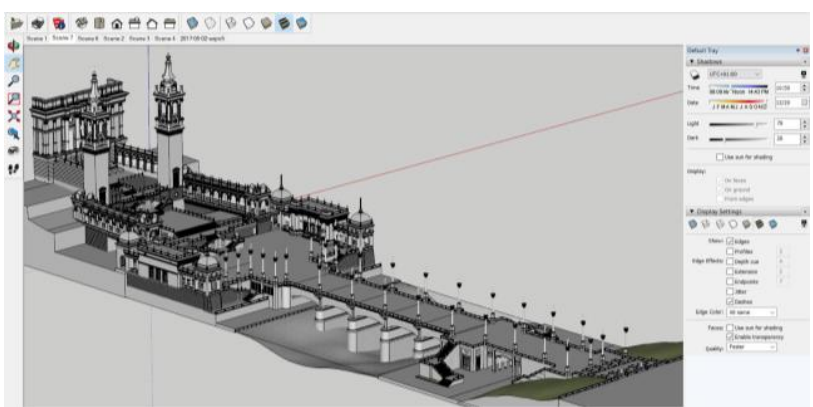

Figure 14. Desktop visualization of the Monumental complex
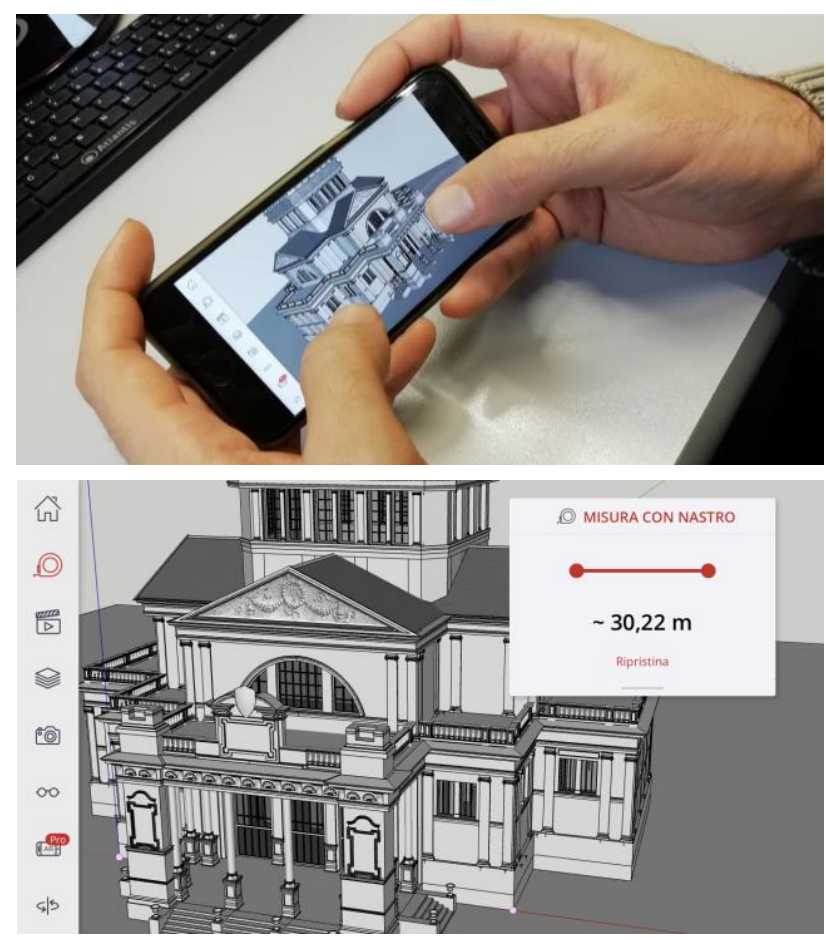

Figure 15. Visualizations from smartphone through SketchUp Viewer app

Another possibility of investigation is the contextualization of the pavilions in the actual context, as if they were still standing in the Valentino Park today. No information can be derived by the actual context because it has changed, but the georeferencing of the 1911 plan (Figure 2) in the actual Valentino Park environment - by identifying common points with the orthophoto obtained with aerial images in GIS software (Figure 16) - assist the positioning of the 3D model in the actual environment.

Finally, the possibility to visualize the georeferenced models in a desktop app (Google Earth Pro) is tested as easy way to 
contextualize the models in the actual environment of the Valentino Park (Figure 17).

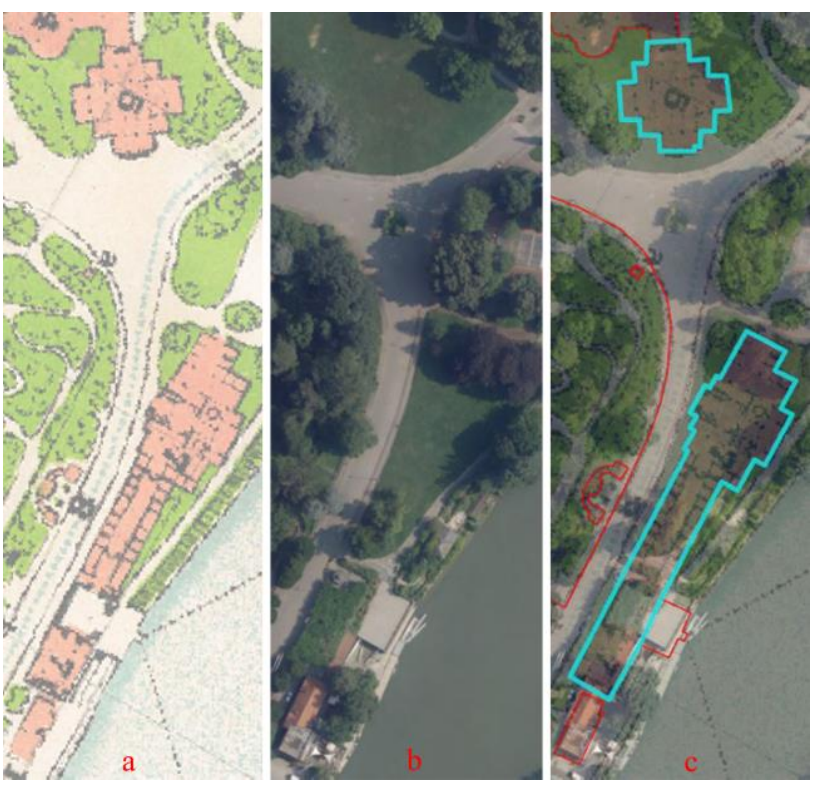

Figure 16. Georeferencing in GIS of the (a) historical map on (b) the orthophoto of the actual Valentino Park to (c) overlay the two data; Pavilions of Hungary and City of Turin are highlighted with light blue boundaries

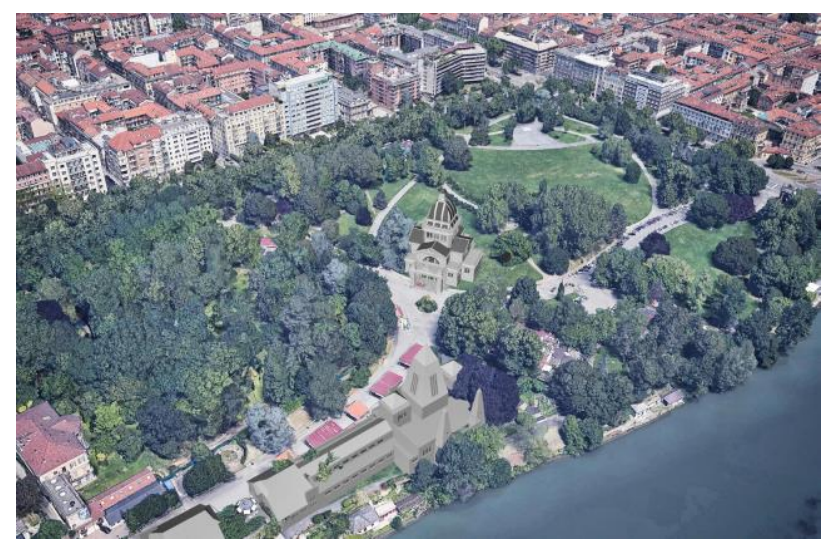

Figure 17. Reconstructed models of the Pavilions of Hungary and City of Turin visualized in the actual context of the Park

\section{CONCLUSION AND FUTURE WORKS}

The reconstruction of three elements belonging to the International Exhibition constitute the first attempt for the entire 3D visualization of Turin 1911 World's Fair. This goal constitutes a cultural heritage memory of the early XX century in which the pavilions are an expression of different architectural style, representing the identity and power of participating nations. These three case studies have been chosen as a sample to analyse various challenges to be tackled for the entire virtual reconstruction of the 1911 World's Fair as a complex event to study. The present research proposes a workflow based on a combination of sources, solutions and software that allow to create an accurate $3 \mathrm{D}$ model on the basis of the geometrical content of old images and drawings. Each digital reconstruction requires preliminary operations to guarantee a scientific approach and has to consider the possible uses. In particular, this study analyse the difficulties encounter during archival research, technical analysis of documentation, digitization of the material, combination and comparison between different data to obtain 3D models. The challenges to digitize fragile and folded papers requires further analysis to improve the quality of the digitization and the speed of the process. The analysis of the material need the awareness of the operator, but can be assisted by the use of a common reference system for different material, once digitised, therefore the ability to integrate disparate data constitutes a plus value to obtain more reliable models of past environments. This is true also in case of numerous drawings but few images and no common elements with the actual context. Then technical problems related to the modelling of structures characterized by different dimensions, shapes and style are analysed in detail, in this case the main problems that can be stressed are related to the geometrical complexity of the structure and the presence of repetitive elements that influence both the time required for the modelling phase and the file size. Nonetheless, the choice of an extremely flexible software integrated with a lot of useful tools and plugins and the interoperability file formats, as SketchUp Pro, ease the operator in achieving the goal. In fact, in this case, the employment of specific software for each step (digitization of documentation, redrawing, modelling, visualization, georeferencing) and their interoperability has permitted the creation of the 3D models and their visualization. The potentiality of the digital reconstruction of no longer existing architectures is not limited to visualization, as realistic views, desktop and online navigation with different devices, previously illustrated. Indeed $3 \mathrm{D}$ models represent starting points for further uses, especially relevant in the case of interdisciplinary studies, as pursued by the Turin 1911 project.The next steps of the present project aim to develop different uses of the obtained models. Firstly, the transposition of these non-parametric 3D models in HBIM software is under analysis, it is necessary to verify the process required to achieve the goal of associate geometrical and textual parameters, positioning and type of visualization properties to each object of the already existing 3D models. This process enriches the geometrical models and their management, increasing the knowledge of these architectures; nonetheless, it is not an automatic procedure but requires preliminary operations and evaluation before the import of each element according to its geometrical complexity and possibility of parametrization (Figure 18).

Then video animation and virtual and augmented reality visualization can be considered as well as means of communication; the latter also enables the interaction between model, context and user in a 3D visualization. Secondly, desktop GIS and WebGIS visualizations tests (Figure 19) are ongoing to collect different sources in a unique georeferenced system. In this case the systematic storage of historical and current data - both visual and textual - in a georeferenced database permitting the comparison between different scenarios and related information over time, but also enabling the linkage between 2D data and 3D models is under development.

The application of technology to an interdisciplinary project that involves the cooperation between several experts as historians, scholars, architects, geomatics, digital technology specialists - constitutes a powerful and flexible mean for the analysis of a complex phenomenon, as in the present case of the 1911 World's Fair that implies cultural, visual and sociopolitical complexities. In this context the role of geomatics constitutes an essential link in this chain and the development of solutions and workflow considering the entire process - from the collection of data to the use of the 3D models - are more and more exciting and promising as new ways of experience, understand complex events and more in general powerful for the transmission of culture. 


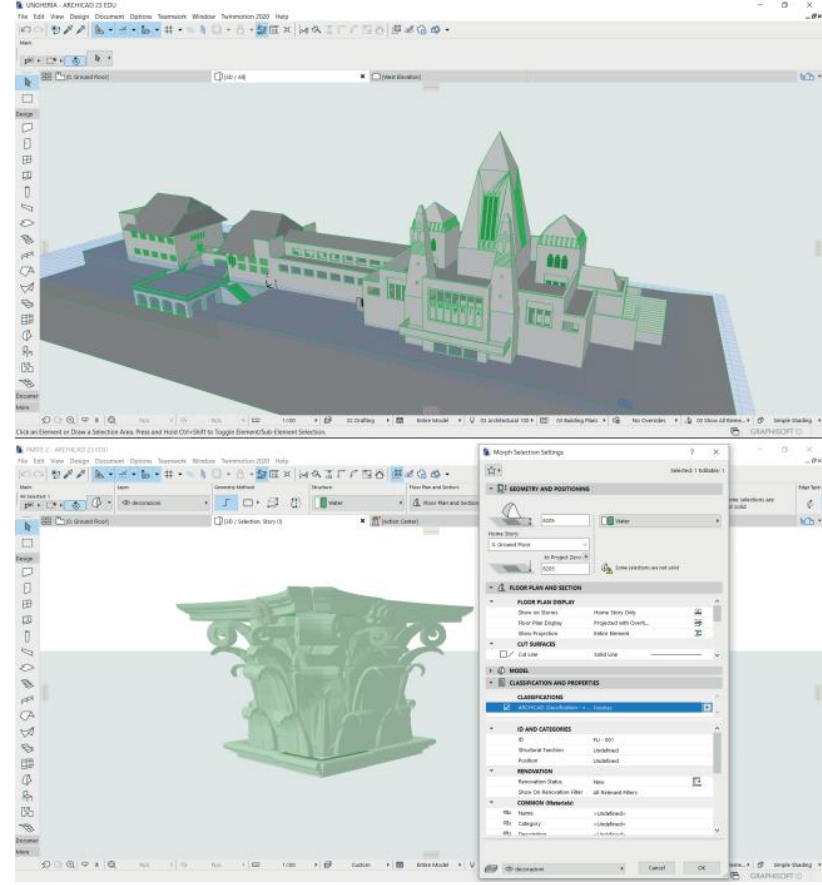

Figure 18. First test for the transposition of the non-parametric 3D model into a parametric 3D model: (up) the simple case of the Pavilion of Hungary, (down) the partial parametrization of a complex capital of the Monumental complex

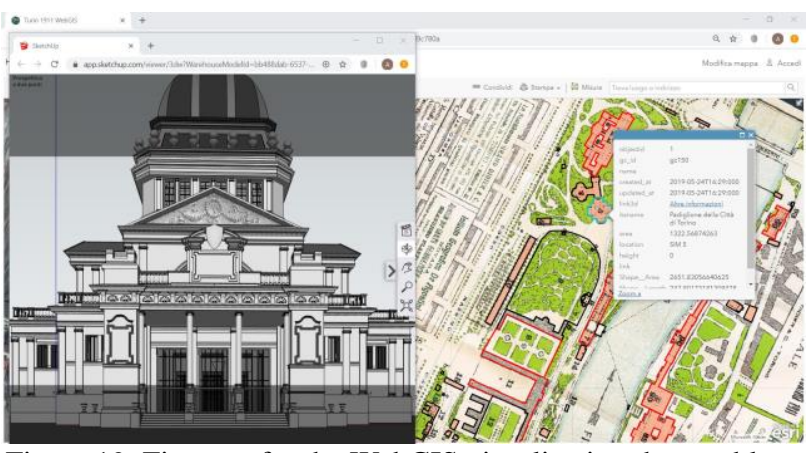

Figure 19. First test for the WebGIS visualization that enable to connect the geometry of the Pavilion of the City of Turin with associated information and the 3D model

\section{ACKNOWLEDGEMENTS}

The authors would like to thank Fondazione Marazza staff for their support in archival research and precious cooperation. The authors would also like to thank the members of the Laboratory "Geomatics for Cultural Heritage" $(\mathrm{G} 4 \mathrm{CH})$ of Politecnico di Torino for the assistance and S. Scovazzo for the HBIM further developments.

\section{REFERENCES}

1911. La guida rimborsabile tricolore di Torino $e$ dell'esposizione del 1911. F. De Rio, Milano, MI, Italy.

1911. Exposition Internationale de industries et du travail de Turin, 1911: catalogue spécial officiel de la section française. Devambez, Paris, France.

Apollonio, F., Fallavollita, F., Giovannini, E., Foschi, R., \& Corso, S., 2017: The reconstruction of drawn architecture. Studies in Digital Heritage, 1(2), 380-395. doi.org/10.14434/sdh.v1i2.23243.

Bassignana, P. L., 2011. Torino 1861-2011 Storia di una città attraverso le esposizioni. Edizioni del Capricorno, Torino, TO, Italy.

Beltrami, C., Cavezzali, D., Chiabrando, F., Iaccarino Idelson, A., Patrucco, G., Rinaudo, F., 2019: 3D digital and physical reconstruction of a collapsed dome using SfM techniques from historical images, Int. Arch. Photogramm. Remote Sens. Spatial Inf. Sci., XLII-2/W11, 217-224, doi.org/10.5194/isprsarchives-XLII-2-W11-217-2019.

Bitelli, G., Dellapasqua, M., Girelli, V.A., Sbaraglia, S., Tinia, M.A., 2017: Historical photogrammetry and terrestrial laser scanning for the 3D virtual reconstruction of destroyed structures: a case study in Italy, Int. Arch. Photogramm. Remote Sens. Spatial Inf. Sci., XLII-5/W1, 113-119. doi.org/10.5194/isprs-archives-XLII-5-W1-113-2017.

Chiabrando, F., Sammartano, G., Spanò, A., Spreafico, A. 2019: Hybrid 3D Models: When Geomatics Innovations Meet Extensive Built Heritage Complexes. ISPRS Int. J. Geo-Inf., 8, 124. doi.org/10.3390/ijgi8030124.

Condorelli, F., Rinaudo, F., 2018: Cultural heritage reconstruction from historical photographs and videos, Int. Arch. Photogramm. Remote Sens. Spatial Inf. Sci., XLII-2, 259-265, doi.org/10.5194/isprs-archives-XLII-2-259-2018.

Cornaglia P., 2001: A magyar pavilon az 1911-es Torinói Világkiállításon = Il padiglione ungherese all'Esposizione Internazionale di Torino del 1911, Pavilon, OMvH Magyar Èpítészeti Múzeum Pavilion Alapítvány, Budapest, Hungary, 79-96.

Della Coletta, C., 2006. World's Fairs Italian-Style: The Great Exhibitions in Turin and Their Narratives, 1860-1915. University of Toronto Press, Toronto, ON, Canada.

Maiwald, F., Vietze T., Schneider, D., Henze, F., Münster, S., Niebling, F., 2017: Photogrammetric Analysis of Historical Image Repositories for Virtual Reconstruction in the Field of Digital Humanities, Int. Arch. Photogramm. Remote Sens. Spatial Inf. Sci., XLII-2/W3, 447-452. doi.org/10.5194/isprsarchives-XLII-2-W3-447-201.

Moriondo, C., 1981. La favolosa esposizione. Daniela Piazza, Torino, TO, Italy.

Münster, S., Niebling, F., Bruschke, J., Barthel, K., Friedrichs, K., Kröber, C., Maiwald, F., 2020: Urban History Research and Discovery in the Age of Digital Repositories. A Report About Users and Requirements, in Digital Cultural Heritage, Kremers, Horst (editor), Springer, 63-84, doi.org/10.1007/978-3-03015200-0_5.

Rodríguez-Gonzálvez, P., Guerra Campo, Á., Muñoz-Nieto, Á. L., Sánchez-Aparicio, L. J., González-Aguilera, D., 2019: Diachronic Reconstruction and Visualization of Lost Cultural Heritage Sites, ISPRS Int. J. Geo-Inf., 8, 61. doi.org/10.3390/ijgi8020061. 